RESEARCHARTICLE

\title{
Identifying Effective and Successful Teaching Strategies Using the PERIA Model
}

\author{
Alina M. Zapalska*, Alex Waid, Melinda McGurer, and Erik Wingrove-Haugland
}

U.S. Coast Guard Academy, USA

\begin{abstract}
The purpose of this paper is to outline effective strategies that increase student learning and stimulate the development of reflective thinking in undergraduate courses. Specifically, it shows that class activities using the PERIA model (Preparation, Experience, Reflection, Integration, and Application) can increase student learning in a variety of technical and non-technical courses. The first example illustrates the use of games and simulations to stimulate and encourage reflective learning in an economics course where students discuss, reflect, practice and apply what they learned from the simulation. The second technique illustrates cooperative learning using small group discussions, case studies, and brief presentations in the context of a discussion-oriented moral philosophy class. The third example uses a Nearpod application in an active, learner-centered Spanish classroom to encourage metalinguistic discussion, communicative uses of language, and even intercultural comparisons. The final example demonstrates how a mathematics course, historically dependent upon lecture, can use consulting projects and a cyclical approach to the PERIA process to increase student learning.
\end{abstract}

\section{Keywords}

Student learning, PERIA process, teaching strategies

Open Access

Citation: Zapalska, A. M, Waid A, McGurer $M$, and Wingrove-Haugland E. Identifying Effective and Successful Teaching Strategies Using the PERIA Model. Interdisciplinary Education and Psychology. 2019; 2(3):1.

Received: January 22, 2019 Accepted: July 52019

Published: July 19, 2019

Copyright: @ 2019 Zapalska A. M. This is an open access article distributed under the terms of the Creative Commons Attribution License, which permits unrestricted use, distribution, and reproduction in any medium, provided the original author and source are credited.

Corresponding author:

Alina M. Zapalska, U.S. Coast Guard Academy, USA

E-mail: Alina.M.Zapalska@uscga.edu

\section{Introduction}

For many years, the lecture mode has been the most extensively used instructional strategy in college classrooms (Wenglinsky, 2000). This teacher-centered approach of instruction, in which the instructor speaks in front of students who inactively take notes, provides a way to communicate a large amount of information to many students but does not ensure that the students learn, understand, and are able to apply the material (Hativa, 2000). The traditional lecture format assumes an unrealistic level of student understanding, minimizes feedback from students, and disengages students from the learning process, causing information to be quickly forgotten (Bligh, 2000). However, the traditional lecture can be an effective way to achieve instructional goals when used in conjunction with active and student-centered teaching strategies (Weimaer, 1990; Felder \& Brent, 2001).

Alternative methods of instruction have been implemented in undergraduate classrooms with successful results in meeting students' learning styles: oral, verbal, kinesthetic, and written styles (Holter, 1994; Omaggio-Hadley, 2001; VARK, 2006). A better understanding of active and student-centered teaching techniques in an undergraduate program can also facilitate the improvement of teaching; while recognizing the attributes of effective instruction allows matching instructional techniques with specific courses and students' learning skills (Wenglinsky, 2002). For example, cooperative learning has been associated with gains in achievement, interpersonal skills, and positive attitudes toward learning (Cohen, 1994; Johnson \& Johnson, 1989). Beyond these overall gains, research also suggests that cooperative learning may lead to gains in critical thinking skills (Johnson \& Johnson, 1990).

Active learning in the college classroom has been strongly advocated (Maier \& Keenan, 
1994; Smith, 1992) and used to promote educational goals in a variety of college disciplines. Active and cooperative learning requires students to work together to experience, analyze, criticize, and solve problems instead of simply taking notes (Cooper \& Mueck, 1990). Requiring students to become active learners provides them with practical experience and promotes learning via experiential learning techniques (Lewis \& Williams, 1994). The goal is to let students experience something new from active participation in learning together, and then encourage reflection about their experience. This reflection helps students develop new skills of thinking, reflecting, analyzing, and applying (Kolb, 1984; Lewis \& Williams, 1994).

Similarly, situated learning, based on everyday interactions, where reflection based on the experience of social relations, cultural history, and artifacts and physical dimensions of the learning environment, promises effective learning as well as a broader perspective for research and practice in instructional design (Wilson \& Myers, 2000). This instructional method, advanced by Jean Lave and Etienne Wenger in the 1990s, followed the research of Dewey and Vygotsky (Clancey, 1995). Stein (1998) argued that situational learning can be enhanced when students actively participate in the learning experience from the real activities of daily living that includes: field trips, cooperative education and internship experiences, music and physical education, and laboratories where students are involved in activities which replicate actual work settings.

This paper builds upon the existing theories and models (Kolb, 1984) of experiential, situational, collaborative, and reflective learning to develop a multi-stage reflective learning model that can be used to structure any reflection-on-action technique. The model, called the Preparation, Experience, Reflection, Integration, Application (PERIA) process or model, can be adapted to any learning technique that is expected to develop reflective thinking skills. This paper stresses that both Preparation stage and Application stage are essential elements of the Kolb model of experiential learning. Both stages allow the process of experiential learning to be delivered more efficiently with greater student involvement in the learning process.

The paper illustrates how various learning instruments using the PERIA model can give students hands-on experience designed to stimulate and encourage both experiential learning and reflective learning. While actively participating in class activities or assignments, students formulate and come to understand important concepts based on continuous experience, questioning, and reflection. Requiring students to discover, experience, reflect, integrate, and apply the concepts they have learned provides practical experience and develops the reflective thinking skills that students vitally need.

The first example, The Market Game, illustrates a case of experiential learning for active and reflective experimentation and the development of effective and reflective skills using the PERIA process while players actively participate in a game that simulates an artificially created market. After completing a simulation game, students discuss, reflect, integrate, and apply what they learned from the simulation.

The second example, Ranking Wars Morally, shows how small group discussions and cooperative learning can enhance a discussion-oriented class. While discussion is less efficient than lecture in covering information, students retain the information covered in discussions more because they are actively integrating it into their pre-existing knowledge, rather than passively absorbing it. Even discussion, however, needs to be enhanced by other active and cooperative learning techniques (Rice, 1990). Cooperative learning theory recognizes that students can learn as much from each other as they do from the instructor, especially when they work together (Johnson et al., 1991). Cooperative learning is the pedagogy within which students are active constructors of knowledge in the learning process instead of passive receivers of any given knowledge (Liang, 2002). The authors support the claim that cooperative learning must be based on five elements: positive interdependence, face-to-face interaction, individual accountability, interpersonal and social skills, and group processing (Johnson \& Johnson, 2008).

The third example, using Nearpod in a world language classroom, demonstrates how metalinguistic analysis, that is, reflection on the use of language, can help students learn from one another and better acquire grammatical structures. The Nearpod activity is built on and followed up with interactive activities to afford students the opportunity to continue the acquisition process with one another. Finally, during the whole-group sharing portion of the process, the students should be able to produce original language using the new grammar structure with minimal involvement of the instructor. Beyond learning a new linguistic 
structure, the activity emphasizes the fact that world language learning is inherently an active, social, communicative application of knowledge.

The final example, using group projects in a Linear Regression course, demonstrates how traditional lecture instruction and homework in a content dominated course can be supplemented by the PERIA process. The course projects guide the students to apply mathematical analysis to real-world problems using a cyclical approach to reflection and integration of course concepts. Working with real data, rather than textbook created examples, requires a higher level of reflection and critical thinking that is essential for any student of applied mathematics. By working within the team environment to achieve a successful resolution to a non-textbook and sometimes initially unclear problem, students are forced to reflect upon and integrate the breadth of material learned throughout the course. This application of the PERIA model demonstrates that the model can be effectively implemented over a longer time scale than a single class or chapter in technical fields of study.

In sum, the purpose of this paper is to present teaching attributes and strategies that are associated with instructional effectiveness for development of experiential and reflective learning. Based on examples experienced from the undergraduate classroom at the U.S. Coast Guard Academy, the paper underlines several teaching strategies to determine how each of these modes of teaching contribute to the effectiveness of teaching. The goal is to share the strengths and successes of instructional techniques and attributes. The last section of this paper presents an example of empirical evidence that the use of PERIA model increases efficiency of instruction as students' achievement levels were assessed using a simple in-class evaluation technique.

\section{Literature Review}

Undergraduate instruction has often been a passive experience. The need to improve methods of instruction to promote high levels of academic achievement is one of the primary goals of curriculum development. It is generally agreed that traditional patterns of instruction do not help students learn how to think critically or develop good interpersonal skills (Zapalska \& Brozik, 2001). In the last three decades, there has been substantial research done on the effectiveness of learning models that involve experiential learning, active learning, or taskbased teaching (Klopfer, 2005, Kirkley \& Kirkley, 2005).

Today, academic faculty members are increasingly using variety of learning techniques and methods to help students achieve high level of cognitive skills (Johnson \& Johnson, 1991). Collaborative learning in the college classroom has been strongly advocated and used to promote educational goals (Smith \& Johnson, 1992).

By definition collaborative or cooperative learning requires students to work together in small groups to analyze, criticize, and solve problems. They actively participate in the classroom instead of simply listening to a lecture and possibly taking the notes (Johnson \& Johnson, 1989). Students can benefit from replacing a traditional lecture with active participation. Also using existing knowledge and skills, students working together can integrate new information, select what is important, think strategically, and learn to make inferences beyond the information given. Active group involvement is the key to stimulating critical thinking (Smith \& Johnson, 1992).

A variety of related theories and models of learning have emerged to establish the learner's activity as the central principle of any learning and teaching environment. The learnercentered theories are based on a principle that students learn effectively and retain learned information best when they are actively involved in the learning process, and are motivated to act and to discover facts and connections for themselves by being presented with complex tasks that require autonomous problem-solving.

Various terms have been used to name the process of learning from experience. John Dewey (Dewey, 1916) was the first who discussed learning by doing, while Wolfe and Byrne (1975) used the term experienced-based learning. Experiential learning was later comprehensively outlined by Kolb (1984) where the author emphasized reflection on direct and concrete experience. The AACSB Task Force (1986) used the term applied experiential learning, combining the learning from the real-world situation with the necessary condition of the application of concepts, ideas and theories to the interactive setting.

Much of the research on experiential learning theory has focused on the concept of learning 
style using the Kolb Learning Style Inventory (KLSI) to assess individual learning styles (Kolb, 2007). Kolb (1984) and Shon (1983) state that experiential learning relates to participation and critical reflection on that participation. Experiential learning is where the learner participates in an activity, reflects on the activity to make generalizations, and then applies in new situations. Also, the concept of deep learning describes the developmental process of learning that fully integrates the four modes of the experiential learning cycle - experiencing, reflecting, thinking and acting (Jensen \& Kolb, 1994; Border, 2007).

Over the years, experiential learning became a holistic philosophy of education based on the notion that an individual's life experiences, education and work play a central role in their learning and understanding of new knowledge (Kolb \& Kolb, 2009). Experiential learning has been considered not only a set of tools and techniques that provides students with a range of experiences, but as a continuous process where students bring their own knowledge, ideas, beliefs and practices - at different levels - to their understanding and interpretation of new information (Ambrose et al., 2010). Experiential learning can be used as a method of instruction to support a personalized approach to learning in a higher education context that often values the student undertaking learning in a variety of campus-based, project-based, work-integrated and community contexts.

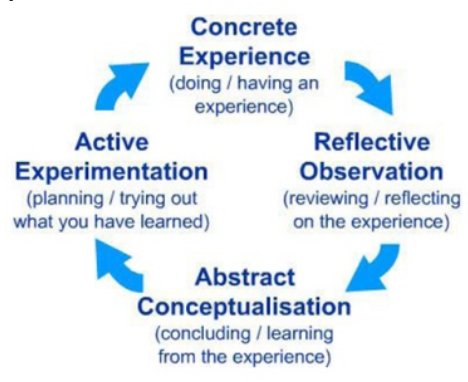

Figure 1. Kolb Learning Cycle

Source:McLeod, S.A. (2010). Kolb Learning Styles: http://www.simplypsychology.org/ learning-kolb.html

Experiential learning theory relies on the fundamental belief that learning occurs when individual players are actively involved with concrete experiences of new concepts and are required to reflect upon their experiences. David Kolb's book Experiential Learning (Kolb 1984 ) is the best-known presentation of the approach to reflective and experiential learning. Kolb's four-stage model of learning is the classical foundation for experiential learning. Kolb's learning styles theory provided a powerful foundation for reflection as a way of learning and for the use of reflective practice (Kolb, 1984;Jarvis, 1987, 2004). Kolb (1984) has depicted experiential learning as a four-stage cycle that begins with concrete experience, followed by reflective observation, abstract conceptualization and active experimentation. This sequential process enables learning to occur "...through a process whereby knowledge is created through the transformation of experience..." (Kolb, 1984, pp. 41) as illustrated in Figure 1 and Table 1.

Table 1. Kolb: Four Stages of Experiential Learning

Concrete Experience: This is the first step of the experiential learning process. Concrete Experience sees the learner involved in a new experience or situation. This also includes a reinterpretation of an existing experience.

Reflective Observation: The second step of Kolb's theory, reflective observation, involves systematic reflection on the new experience. This is an analytical step in which the learner consciously thinks about what they have just experienced. A particularly important aspect of this step is the realization of inconsistencies between experience and understanding.

Abstract Conceptualization: The learner delves deeper into their thinking about the subject. In this step, the learner constructs a new idea, or modifies an existing concept to explain their observations.

Active Experimentation: The final step of the process involves using these new theories to solve problems and make decisions. By applying their newly-conceived understanding of the world around them, they are demonstrating their newfound knowledge. The process enters a new cycle when the learner uses this experimentation to create a new Concrete Experience. 
Source: Kolb, D.A., Boyatzis, R.E., Mainemelis, C. (1999). Experiential Learning Theory: Previous Research and New Directions. Case Western Reserve University; Kolb, D.A. (1984). Experiential Learning: Experience as the Source of Learning and Development, Englewood Cliffs, NJ: Prentice Hall.

Kolb argued that students have a strong preference for a given learning style and they tend to learn more effectively if learning is orientated according to their preference. He proposed that an individual learner moves through a spiral of immediate experience which leads to observations and reflections on the experience. Based on Table 1, the author's four-stage learning cycle shows how experience is translated through reflection into concepts, which in turn are used as guides for active experimentation and the choice of new experiences. In the first stage of concrete experience, students actively experience an activity. During the second stage of reflective observation, students consciously reflect back on their experiences. These reflections are then absorbed and linked with previous knowledge and translated into abstract concepts or theories, which suggest new ways to adjust to the experience that can be tested and explored. In the third stage of abstract conceptualization students attempt to conceptualize a theory or model of what they observed. The fourth stage of active experimentation provides students with an opportunity to test a model or theory or plan for a forthcoming experience.

Other authors who support Kolb's experiential learning stress that experience alone does not guarantee learning; constantly questioning and reflecting on experiences is also necessary in order to transform them into learning (Boyd \& Fales, 1983; Hutchings \& Wutzdorff, 1988; Lewis \& Williams, 1994). Reflection is necessary not only in order to step back, ponder, question, and evaluate one's own experiences, but also to ensure that the knowledge extracted from these experiences is relevant to other experiences. The paper argues that structuring various learning strategies using the multi-stage, the Preparation, Experience, Reflection, Integration, Application (PERIA), model increases effectiveness at stimulating the development of reflective learning skills. The paper contributes to the experiential learning theory by illustrating the PERIA model to provide students with hands-on experience designed to stimulate and encourage both experiential learning and reflective learning. The assessment process presented on this paper illustrates that the PERIA model as an integrated method of teaching can enhance student learning participation through preparation, experience, reflection, integration, and application.

\section{The PERIA Process for Experiential and Reflective Learning}

This paper builds upon the existing theories and models of experiential and reflective learning to develop a five-stage reflective learning process. More specifically, the authors use the Reflection Integration Model (RIM) that is a four-component process based on the following stages: Pre-experience-Experience-Reflection-Integration (Hutchinson \& Allen, 1997). The RIM process is based on an experiential learning theory, which assumes that: (1) reflective learners learn from their experience; (2) the learning outcomes of the experience depend on whether the experience is processed through reflection; and (3) the personalizing of the learning is dependent on the integration of the reflection. In contrast, the PreparationExperience-Reflection-Integration-Application (PERIA) model or process offers a way to structure experiential learning activities to help students become experiential and reflective learners. As both experience and reflection facilitate adult learning, the PERIA process represents the essential ingredients for turning experience into meaningful and reflective learning. The PERIA process can be applied to any learning technique where each student engages in experimentation and reflection that requires preparation stage prior to experience and reflection and application process after integration as presented in Figure 2. The steps must be thought through prior to beginning any learning activity. Proper identification of the exercise's goals and boundary conditions greatly simplify design and construction of experiential learning activities.

RIM PROCESS: Pre-experience $\rightarrow$ Experience $\rightarrow$ Reflection $\rightarrow$ Integration

PERIA PROCESS: Preparation $\rightarrow$ Experience $\rightarrow$ Reflection $\rightarrow$ Integration $\rightarrow$ Application

Figure 2. The RIM and PERIA Process 


\section{Preparation}

While Kolb (1984) saw experiential learning as a four-step process beginning with concrete experience, this paper presents that a fifth step is needed prior to experience: preparation. In this stage, the instructor introduces students to the upcoming experience and background information. During this step, the instructor should highlight the most important elements of the activity and review the aspects of the course material that are most relevant. However, the instructor must not reveal the likely outcome of the experience; doing so undermines the students' sense of reaching this outcome themselves, and may distort or bias their experiences. While this step is often overlooked or taken for granted, it is crucial to the success of experiential learning. Students with no preparation are likely to focus on aspects of the experience that are unimportant or irrelevant to the course material, while missing the aspects of the experience that are crucial for experiential and reflective learning.

\section{Experience}

The actual experience can take many different forms. The four examples that follow include playing a game, participating in small-group discussions to reach an evaluative consensus, engaging in a computer-based creative activity, and problem-solving in small groups, but these are only four examples of activities that can promote experiential and reflective learning. Regardless of the activity used, learning in this stage takes an active form - the learners are actively engaged in the activity, rather than simply watching a video or listening to a lecture. At this stage, students rely on feelings, rather than on a systemic approach to problems and situations. Students get the most out of experiential activities if they are open-minded and adaptable to change; instructors must also be open-minded and ready to change the experiential activity if it is not producing the results needed for productive reflection.

\section{Reflection}

After the experiential activity, students look back on the experience, make observations, and reflect on or discuss how it went. Students share their results, reactions, and observations with their peers, and discuss how the experience was carried out. They may also review the activities and tasks to check that they were completed properly and to make changes that might improve the outcome. In this stage of the learning process, students start understanding ideas, concepts, and situations from different points of view by reflecting on what they did and learned and comparing it to what other students did and learned. Reflection is the key to making experience meaningful. By thinking reflectively about an experience, students reconfigure their thoughts and find a connection between theory and practice. The students' experiences may be re-examined through reading, writing, speaking, and listening. The reflection method or combination of methods to be used is determined by the outcome desired. Class discussions, debates, or debriefing sessions are valuable tools that students can use to discuss and reflect on their experiences. The writing can be processed in a group format if this is appropriate or as homework to further enhance reflective learning. Depending on the developmental level of the students and their readiness to engage in the reflective process, the teacher may allow a free form of expression or provide for a highly structured experience.

\section{Integration}

Every student approaches an experiential activity with a unique set of conceptual schema, including a unique conceptualization of the material covered in the course. Long-term retention requires integrating new information and new experiences into these previously existing conceptual schemas. In this step, students make connections and links between the insights they have gained through reflecting on the experience and their conceptual schema, including the theories, knowledge, or methods they have gained previously in the course. By the end of this stage, learning involves using theories, logic, and ideas, rather than feelings, to understand problems or situations.

\section{Application}

In this step, students apply what they learned in the experience (including the insights gained by reflecting on the experience and fitting it into their past experiences and conceptual schema) to a similar or different situation. They discuss how the newly learned process or concept can be applied to other situations, and how it can be useful in future situations. This process of applying lessons learned through experiential learning, reflection, and integration transforms them from abstract lessons that students might forget, into practical skills that will 
be reinforced by repeated use in a variety of situations.

The next sections of the paper illustrate how various Coast Guard Academy faculty members have developed effective experiential learning activities which use the PERIA model to promote and develop critical thinking and problem-solving skills.

\section{Example 1: Experiential Learning with the Use of Games and Simulations (Economics Course)}

The use of games and simulations can help students develop new skills and ways of thinking, provided the students engage in active reflection about the experience. The PERIA process provides a structure which ensures that games and simulations will include the essential ingredients for turning experience into meaningful learning. The Market Game shows how the PERIA process helps ensure that games and simulations are effective.

Table 2. Individual Trading Lists

\begin{tabular}{|c|c|c|c|c|c|c|c|}
\hline \multirow{2}{*}{\begin{tabular}{|l} 
TO TRADE \\
DUCK
\end{tabular}} & \multicolumn{2}{|c|}{ FAMILY: AMY } & \multirow{2}{*}{$\begin{array}{l}\text { NEEDS } \\
180\end{array}$} & \multirow{2}{*}{\begin{tabular}{|l} 
TO TRADE \\
DUCK
\end{tabular}} & \multicolumn{2}{|c|}{ FAMILY: BOB } & \multirow{2}{*}{$\begin{array}{l}\text { NEEDS } \\
180\end{array}$} \\
\hline & 200 & CHICKEN & & & 150 & CHICKEN & \\
\hline GOOSE & 120 & CARDINAL & 750 & CARDINAL & 160 & GOOSE & 60 \\
\hline ROBIN & 120 & PARROT & 90 & PARROT & 300 & ROBIN & 80 \\
\hline SEA GULL & 150 & CROW & 30 & SEA GULL & 150 & CROW & 30 \\
\hline TITMOUSE & 240 & BLUE JAY & 80 & TITMOUSE & 240 & BLUE JAY & 80 \\
\hline CANARY & 90 & PIGEON & 180 & PIGEON & 300 & CANARY & 90 \\
\hline TO TRADE & \multicolumn{2}{|c|}{ FAMILY: CARRIE } & NEEDS & TO TRADE & \multicolumn{2}{|c|}{ FAMILY: DANIEL } & NEEDS \\
\hline DUCK & 150 & CHICKEN & 240 & CHICKEN & 120 & DUCK & 300 \\
\hline GOOSE & 80 & CARDINAL & 750 & CARDINAL & 160 & GOOSE & 60 \\
\hline ROBIN & 120 & PARROT & 60 & PARROT & 180 & ROBIN & 60 \\
\hline CROW & 150 & SEA GULL & 80 & SEA GULL & 100 & CROW & 20 \\
\hline BLUE JAY & 200 & TITMOUSE & 320 & BLUE JAY & 200 & TITMOUSE & 480 \\
\hline PIGEON & 180 & CANARY & 120 & CANARY & 120 & PIGEON & 180 \\
\hline TO TRADE & \multicolumn{2}{|c|}{ FAMILY: ELLEN } & NEEDS & TO TRADE & \multicolumn{2}{|c|}{ FAMILY: FRED } & NEEDS \\
\hline CHICKEN & 90 & DUCK & 300 & CHICKEN & 90 & DUCK & 400 \\
\hline CARDINAL & 240 & GOOSE & 90 & CARDINAL & 240 & GOOSE & 90 \\
\hline ROBIN & 160 & PARROT & 150 & PARROT & 120 & ROBIN & 60 \\
\hline CROW & 150 & SEA GULL & 120 & SEA GULL & 100 & CROW & 20 \\
\hline TITMOUSE & 160 & BLUE JAY & 120 & TITMOUSE & 160 & BLUE JAY & 120 \\
\hline CANARY & 90 & PIGEON & 240 & PIGEON & 120 & CANARY & 90 \\
\hline
\end{tabular}

\section{Stage 1: Preparation}

Before the Market Game begins, the players are informed that they will be involved in an experiment to discover and experience themselves concepts such as: barter economy, wealth, shortages and surpluses, and the role of market forces in determining the market equilibrium. The class is divided into six families and depending on class size, each family can be of 1 to 3 students. Each family obtains an Individual Trading List (Table 2) where birds listed on a left-hand size represent what familieshave. All birds listed on a right-hand size represent what birds are needed. Table 3 represents a market supply/demand sheet specifying the supply, demand, and market status of each group of birds. 
Table 3. Supply/Demand Master Matrix

\begin{tabular}{|c|c|c|c|}
\hline Item & Quantity Supplied & Quantity Demanded & Market Status \\
\hline Duck & 500 & 1,000 & Shortage \\
\hline Chicken & 300 & 600 & Shortage \\
\hline Goose & 200 & 300 & Shortage \\
\hline Cardinal & 800 & 1,500 & Shortage \\
\hline Parrot & 600 & 300 & Surplus \\
\hline Robin & 400 & 200 & Surplus \\
\hline Crow & 300 & 100 & Surplus \\
\hline Sea Gull & 500 & 200 & Surplus \\
\hline Blue Jay & 400 & 400 & Even \\
\hline Titmouse & 800 & 300 & Even \\
\hline Canary & 300 & 600 & Even \\
\hline Pigeon & 600 & & \\
\hline
\end{tabular}

The instructor explains to the students that the goal of the simulation is for each family to maximize its individual wealth by trying to get all of the birds they need by trading away for birds they need. The students are not informed of the underlying surplus or shortage of birds because any such information could influence the actions and trading behavior of the participants and adversely affect the educational value of the simulation. After the players have a chance to make sure they understand the instructions, and are given a short period to ask general questions and to review the instructions, the game is started by the instructor announcing "the market is now open."When the market opens, students are free to start trades. Trading continues until the close of the market is announced by the instructor. During the simulation, the instructor acts as a facilitator, circulating among the participants, observing trading, listening to negotiating and trade offers, offering suggestions where appropriate, and providing support to the participants. At the end of the trading session, each family reports what birds they bought and birds never traded away.

\section{Stage 2: The Experience}

The Market Game attempts to model a portion of reality in an artificial situation at the level understandable to undergraduate students. Students are engaged in a simulation that creates an experience that has been planned reflectively. When students are engaged in barter, their observations and interactions are directed toward accomplishing the specific goal for the experience of concepts such as barter economy, wealth, shortages and surpluses, and market equilibrium. Students experience that the simulation structure creates the need for participants to identify the relevant information, seek out this information, and act on the information found, even if it is incomplete. Each family that has acquired all of the birds they needed is declared a "winner".Families, who collect all the needed items, and maybe extras, win over families who could not meet their basic needs. Students learn that there can be more than one "winner," but the existence of shortages of some birds makes it impossible for all of the families to win.

\section{Stage 3: Reflection}

The Market Game was structured so that the experiences of students open the reflection followed by the discussion about the simulation and processes observed, experienced, and learned. The debriefing session requires students' participation. When the instructor asks questions, students share their experiences and observations. Students identify winners or losers by determining whether or not each family was able to meet their individual needs. The 
reflection stage concludes with questions that encourage students to reflect on their own personal experience: what did you learn through this experience? What was your moment of failure, success, indecision, doubt, humor, frustration, happiness, and sadness? The discussion that follows the simulation allows students to analyze and reflect on market behavior and stimulates intellectual discussion.

\section{Stage 4: Integration}

At this stage, students are expected to write reports where they integrate economic concepts with their Market Game experience. During the integration stage, students are guided by a set of questions that encourage them to go beyond the experience itself and connect what they learned to what they are studying in class. Students must answer the following questions: Does this experience complement or contrast with what you are learning in class? Are there any social, economic, or political issues or views that have different meanings for you since your experience? What would you change about the situation if you were in charge or played it again? On their reports students identify the major characteristics of the market and the problems that exist within the market. The students' reports integrate their experiences with what they learned from lectures and their readings.

\section{Stage 5: Application}

Any knowledge and skill students develop through the first four stages of the model can be applied in stage five, where more advanced concepts are developed, learned or mastered. During this stage, the instructor moves from questions closely related to economic concepts to more general questions which focus on how students can apply the insights gained through The Market Game. Some of the questions that can be asked include: Did this experience help you understand a particular historical or economic phenomenon? What implications would you draw over debates regarding how markets should be regulated? How will the experience alter your future behavior or attitude? The benefit of the Market Game is that it provides students with a close experience to a real-life role of markets and captures the complexity of market reality with its overlapping decisions, deadlines, and financial and market structure constraints. Classroom experience suggests that The Market Game provides learners with a broad experiential learning environment. It also offers active and reflective experimentation where students have a real educational experience which makes economic theory more meaningful. The game increases the students' motivation and learning and creates intellectual learning that changes attitudes towards learning.

\section{Example 2: Integrating Cooperative Learning with Discussion (Morals and Ethics Course)}

A successful classroom integrates multiple teaching methods, sometimes within a single class meeting. Active learning, cooperative learning, discussion, and case studies are not mutually exclusive candidates for the "best" teaching strategy, but complementary techniques; students learn best when these techniques are used together, and different techniques work best for different materials, with different students, and in pursuit of different pedagogical objectives. Even a class in which discussion, rather than lecture, is the primary mode of instruction should include many other activities designed to promote active, cooperative, and experiential learning. Class discussion, case studies, active learning activities, and working in small groups can often be effectively combined within a single class meeting, as they are in Evaluating Wars Morally.

\section{Stage 1: Preparation}

For a discussion-oriented class, preparation involves students reading course material and coming to class ready to discuss it. This is a major challenge to effective discussions; there are few experiences more discouraging than attempting to hold a discussion on material that most of the students have not read. For this reason, discussion courses must utilize methods for ensuring that students have completed the reading before they arrive in class. In addition, they must include some method for encouraging students to begin analyzing the reading and identifying major points to discuss in class.

Another major challenge with discussion classes is ensuring that discussions are not dominated by a few students, with most students silent and passive. Grading class participation is not enough to prevent this; some students will not be able to answer 
comparative or evaluative questions about the material and may not retain components of the material well enough to respond to instructor questions, particularly in required or core courses in which almost all students have chosen a major unrelated to the course material. This is particularly a problem with discussions involving the entire class; students who are reluctant to participate in a group discussion involving the whole class may be much more willing to speak in a small group of two or three other students. While students have a greater tolerance for class discussions than for lectures, it is important to remember that their toleration for class discussion is limited; they need varied activities during class, or they will grow weary of the discussion.

There are several ways to accomplish these goals; the Moral and Ethical Philosophy course at the Coast Guard Academy, a core course taught mainly to STEM majors, uses the following:

- Very short reading assignments and a clear expectation student will read every word;

- Astudy guide asking questions regarding major points covered in each day's reading;

- $\quad$ "Pop" quizzes using questions drawn directly from this study guide, with answers straight from the text, with pre-announced quizzes on particularly difficult material; and

- $\quad$ Class discussions which include questions from the study guide, as well as more advanced comparative or evaluative questions.

Thus, for a class on Just War Theory, students read a short (8-page, 4,800 words) reading assignment on the historical development and principles of Just War Theory. This reading contrasts Just War Theory (the view that some wars are immoral, and some are not) with both pacifism (the view that all wars are immoral) and realism (the view that no wars are immoral).Students also complete a study guide on the reading; study guide completion rates are excellent, because students are allowed to look at their study guides (but only at their study guides) while taking "pop" quizzes. The class discusses the principles of jus ad bellum - the principles for evaluating the morality of going to war-for approximately 15 minutes, making sure that all students participate and that they understand these principles.

In a class dominated by STEM majors, one of the major challenges is avoiding the perception that the jus ad bellum principles of Just War Theory constitute either a precise, objective formula for evaluating wars morally or a vague set of unrealistic desiderata which mask the fact that evaluating wars morally is completely subjective. It is not enough for the instructor to assert that neither of these views is accurate; students need to discover this themselves. This is accomplished using an exercise called Ranking Wars Morally.

\section{Stage 2: The Experience}

Students are divided at random into groups of three or four and instructed to use the jus ad bellum principles of Just War Theory to rank the following wars as to how morally justified U.S. entry was: World War II, Vietnam, Iraq 1991, Afghanistan 2001, and Iraq 2003. These conflicts, in essence, serve as case studies--but they are case studies with which students are already familiar (this is why Korea is not included); some students may lack some knowledge regarding the beginning of one or more of these conflicts, but the other two or three students can provide it. Students are told that each small group must produce a single consensus ranking from "most justified" to "least justified."

As students discuss in their small groups, with the instructor available to answer historical questions only, they have to integrate their knowledge of history with the principles of jus ad bellum, and then they have to integrate these with the other members of their small group, which requires compromise. At the end of this small-group discussion (which generally takes about five minutes), each small group gives the instructor a $3 \times 5$ index card with their group's ranking. The instructor takes these rankings and quickly compiles them into a single table (this takes minimal class time, since some groups finish earlier than others).

There are usually five or six small groups in a class of 15-20 students; in over 50 iterations of this activity, there have never been completely identical rankings by all groups. The rankings, however, are always remarkably similar: World War II is almost always at the top, followed by Iraq 1991 and Afghanistan (often in different orders); Vietnam and Iraq 2003 are almost always the bottom two (again, often in different orders). Table 4 presents the various small group rankings from a recent class: 
Table 4. The Small Group Rankings (Morals and Ethic Course)

\begin{tabular}{|l|l|l|l|l|}
\hline \multicolumn{1}{|c|}{ Group 1 } & \multicolumn{1}{|c|}{ Group 2 } & \multicolumn{1}{c|}{ Group 3 } & \multicolumn{1}{c|}{ Group 5 } \\
\hline World War II & World War II & World War II & World War II & World War II \\
\hline Iraq 1991 & Afghanistan & Afghanistan & Iraq 1991 & Iraq 1991 \\
\hline Afghanistan & Iraq 1991 & Iraq 1991 & Afghanistan & Afghanistan \\
\hline Iraq 2003 & Vietnam & Iraq 2003 & Vietnam & Iraq 2003 \\
\hline Vietnam & Iraq 2003 & Vietnam & Iraq 2003 & Vietnam \\
\hline
\end{tabular}

After tallying the different rankings, the instructor leads a discussion on why every group ranked World War II first, notes variations in the rankings of other wars, and tells each group with similar rankings to produce arguments defending their relative rankings. In the example above, groups 1, 4, and 5 were instructed to provide arguments defending their claim that Iraq 1991 was more justified than Afghanistan 2001, while groups 2 and 3 were told to produce arguments on the other side. Groups 1, 3, and 5 offered arguments that Iraq 2003 was more justified than Vietnam, while groups 2 and 4 created the opposing arguments. Unlike the previous small group assignment, which required compromise, this assignment allows small groups to work together cooperatively towards a common goal: producing good arguments to defend their group's ranking. Again, these small group discussions take about five minutes. After generating arguments for their rankings, the groups on each side then take turns presenting these arguments to the class in what amounts to a series of short debates; each group presents arguments for their rankings, followed by another group defending the opposite rankings. Groups change sides from one debate to the next; for example, groups 2 and 3 were on the same side in the debate over Iraq 1991 and Afghanistan, but on opposing sides in the debate over Iraq 2003 and Vietnam. If groups are not explicit as to which of the principles of jus ad bellum is at stake in their argument, the instructor asks them to identify the principle.

\section{Stage 3: Reflection}

At the end of these short debates, the instructor points out that, while the rankings were very similar, they were not identical, and asks what that shows about Just War Theory. Class discussion leads to the conclusion that, while Just War Theory does not allow a conclusion that one set of rankings is objectively correct, it provides a method for evaluating wars morally which is not completely subjective. While in some cases it is debatable as to which of two conflicts was more justified, sometimes Just War Theory clearly shows that a particular conflict was more justified than another.

The instructor asks whether these relative rankings show where to draw the line between a justified and an unjustified war, and the class notes that they do not. Even if two groups created identical rankings (as Group 1 and Group 5 did in the example above), someone could argue that World War II was the only justified conflict of these five, and that the other four were not justified, while someone else could argue that Vietnam was the only one of these five conflicts that was not justified, and that the other four were justified.

Finally, the instructor notes that different groups used similar arguments to defend their rankings. For example, groups arguing that Iraq 1991 was more justified than Afghanistan always point out that the U.S. was attacked by al Qaeda in 2001 rather than by the Afghan army; those arguing on the opposite side always note that Iraq attacked Kuwait in 1991 rather than attacking the U.S. directly. The instructor points out that these facts may make these conflicts less justified than World War II (in which the U.S. was attacked directly by the Japanese army), but asks whether these facts allow a definitive statement as to whether Afghanistan 2001 or Iraq 1991 was more justified; the class agrees that they do not. Reflecting on the similarity of these arguments leads the class to see that, even when the criteria of Just War Theory do not result in a clear moral judgment, they provide guidance regarding which arguments are most relevant to evaluating wars morally.

\section{Stage 4: Integration}

After the class reflects on the Ranking Wars Morally exercise, the instructor seemingly moves on to a discussion of the jus in bello principles which evaluate the morality of fighting during war. In fact, however, this discussion quickly leads the class to realize that what they 
just discovered experientially regarding the principles of jus ad bellum is also true of these jus in bello principles: sometimes they produce clear moral evaluations of acts during war, and sometimes they show that a particular act is debatable and help identify key issues in this debate. Through discussion, the class uses jus in bello principles to distinguish between acts that were clearly violations of the rules of war (such as the Mylai massacre), acts that were clearly not violations of the rules of war (such as the decision not to attack Baghdad in 1991) and acts that are debatable (such as the atomic bombings of Hiroshima and Nagasaki).Examining the jus in bello principles allows the class to see what the key issues are in these debatable cases: whether the amount of force used was proportional to the military objective, whether that military objective could have been achieved with a lower amount of force, and whether non-combatants were intentionally targeted. This discussion allows students to integrate what they have learned regarding one part of Just War Theory with what they are about to learn about another part of Just War Theory.

\section{Stage 5: Application}

As the class ends, the instructor asks how students might apply what they learned today about Just War Theory to morality as a whole. The instructor writes "clearly immoral," "clearly not immoral" and "debatable" on the board, and asks the class for examples of actions that fit into each category; a consensus of everyone in the class is required to put something in the "clearly immoral" or "clearly not immoral" category. The class identifies some things (such as murder and slavery) as clearly immoral, other things (such as mixed-race marriages) as clearly not immoral, and yet other things (such as abortion and euthanasia) as morally debatable. The instructor notes that Just War Theory suggests an approach to these debatable issues; look for a set of criteria that, for example, an act of euthanasia would have to meet in order to be justified morally. This application of Just War Theory to issues other than war helps the class see how they can apply the basic idea of a set of criteria that distinguish just wars from unjust wars to a broad range of moral issues.

\section{Example 3: Using Nearpod to Promote Active Communication (World Language Course)}

The use of active, learner-centered activities in the world language classroom has been standard practice in colleges and universities since the mid- to late-eighties. The communicative, task-based world-language classroom of today prefers active student communication to rote memorization and mechanical manipulation of forms. There are many complementary ways to achieve this communication. New technologies have allowed a variety of methods that allow individual mastery of forms to flourish both outside and inside the classroom while continuing to promote communicative efficacy in the classroom (Burston, 2013). This example shows how language instructors can use one such technology, Nearpod, to help students develop both skills in a specific language and general meta-linguistic skills through an active learning exercise called Communication Before Grammar.

\section{Stage 1: Preparation}

In the example discussed herein, students in an elementary Spanish class were asked to learn the present tense of regular verbs in three verb families ("-ar," "-er," and "-ir") and memorize a list of approximately twenty common verbs. Prior to class, students were assigned a series of pages that explained the lexical and grammatical material. Students also had to complete seven online exercises designed to practice and reinforce the material. Each of these was self-corrected by the students online. This approach is currently known as the "flipped classroom."

In addition to this relatively standard preparation for a Spanish class, students drill themselves on the new vocabulary online before coming to class. The instructor configured the online homework system, Pearson's "MySpanishLab" to allow students as many as three attempts per exercise for credit. After the third attempt, the student is shown the correct answer. This flipped approach, in which students teach themselves the material before coming to class, allows class sessions to be much more dynamic and interesting. Rather than beginning by drilling students on the new vocabulary and grammar, the instructor can presuppose a basic familiarity with the new material and focus on the use and application of the information they already learned. Having students look over the material in advance allows the instructor to use class time for application of the new knowledge rather than 
transference of information.

\section{Stage 2: The Experience}

Nearpod, a web 2.0 application that can be easily and cheaply downloaded to portable devices or computers, can be used to quickly verify student preparation, expand the students' knowledge, and deepen their understanding and mastery.

Nearpod is interactive presentation software. Much like other presentation applications such as PowerPoint and Prezi, Nearpod can deliver information via slides. However, Nearpod presentations are not projected for the class or audience members to view on a screen. The students receive the presentation on their personal devices such as computers, laptops, smart phones, or tablets. It is part of what is now called, "Bring Your Own Device" pedagogy. Furthermore, Nearpod allows for user interaction including, but not limited to: multiple choice quizzes, short answer questions, drawing and polls.

Although the flipped model is an excellent way to allow for a more student-centered focus, it only works if students have: (a) actually looked over the material and (b) mastered it sufficiently to apply it in class. To ensure that this is the case, students take a poll on Nearpod, which mimics common clicker-technologies. They are presented with individual verbs, a subject and, for each verb, a series of possible conjugations. The class progresses through these examples one at a time, to ensure that everyone has a relatively strong grasp on the concept of present-tense conjugations. If it is clear that some students are struggling, the instructor can simply move into a traditional lecture mode for a moment and remind students of the conjugations orally or on the board and then move back to the Nearpod presentation.

Having verified that all students have a basic understanding of the material, and having activated the knowledge in the first part of the Nearpod exercise, the instructor proceeds to the second stage of the Communication Before Grammar exercise, in which students are individually creating with the language. Using the short-answer functionality of Nearpod, the instructor poses questions to the students which they must answer using the present tense. In this case, typical questions were, "What do you do on weekends?" "What do your friends do at night?" "What do you do in class?" "What does your instructor do in class?" and other similar examples. In each case, students were asked to answer open-ended questions using different subjects in order to practice conjugating in the present tense in creative and personalized ways. Having students use the new vocabulary and grammar to communicate before they have a complete understanding of it more closely mirrors the experience of native speakers, who are able to use grammar correctly before they learn the formal rules of grammar. $t$ also reminds students that the goal is not to develop an intellectual understanding of Spanish grammar; grammar is merely a means to the end of communicating in Spanish.

\section{Stage 3: The Reflection}

After posing each Nearpod question, the instructor can use the "Share" feature on the Nearpod app to deliver student answers to the entire class anonymously. This allows for a multitude of possibilities regarding meta-linguistic interaction; in particular, it enables the instructor to share good examples in order to discuss what makes them good and to share examples with errors in order to lead the class through the process of correcting them. There is no need to discuss every student's answer; or to identify which students provided which answer; instead, the instructor carefully selects answers that illustrate both accurate use of the new grammar and vocabulary and the errors to which students are most prone.

In the Communication Before Grammar exercise, the instructor does not tell the class if the examples chosen are to demonstrate particularly good examples or examples with errors; instead, the instructor shares a student answer and facilitates a series of checks: "What is the verb?" "What is the subject?" "Do they agree?" "Are there any adjectives?" "Do those agree with the nouns they modify?" and so on. All of these are asked in Spanish and volunteers are chosen to answer them. As the class progresses through the semester, the questions are streamlined until the instructor can simply ask, "Does this sentence look right?"The students have learned to do this kind of on-the-spot analysis automatically and it gives them a powerful tool to gauge their own accuracy. When there are no errors on an example, the instructor simply moves on to the next example, but if there are errors present, the class, not the instructor, corrects the sentence orally or on the board.

In this way, Nearpod provides a space for linguistic creativity, and a low- to no-stakes learning environment where errors do not count against a grade (and are not a source of 
embarrassment), but rather afford students opportunities to develop analytical and interpretive tools as they attempt to understand what their classmates have written.

This exercise is repeated for a few questions; each time, the students look at a limited set of examples from the class to show well-written sentences and demonstrate how to correct errors in Spanish construction.

\section{Stage 4: Integration}

After verifying the class' mastery of the material, the instructor can move away from computer-mediated instruction via Nearpod to the work of face-to-face communication using a peer-to-peer activity. The instructor divides students into small groups and hands out new questions, similar to those used in the Nearpod activity, to ask their classmates. Each student can be asked to record his or her partners' responses for later reporting-out.During this part of the class activity, the instructor moves around the room to ensure grammatical accuracy and communicative effectiveness. If there is an issue with a group, the instructor can serve as a mediator to help the students achieve the task of sharing the required information.

This portion of class involves more creative information exchange; the purpose is no longer principally achieving grammatical accuracy, but facilitating communication, in Spanish. Hopefully, the grammatical issues at hand (here: present-tense conjugation and memorization of new verbs) have begun to retreat into the background in favor of achieving real face-to-face communication.

\section{Stage 5: The Application}

After finishing the small-group interviews, the groups report out to the class, sharing their partners' responses. This forces the students to move from the "I/You" paradigm and into the third-person "He/She/They."

As students report out, the instructor or a class volunteer can write the class' responses on the board for the entire class to see. Once the reporting out is complete, the instructor can then ask questions regarding trends they observe in their classmates' behaviors from the data on the board. This takes the language instruction one step further; after simply reporting on their own or their partners activities, students must make inferences and note trends and communicate them "on the fly" in the classroom. There is no time to prepare for this part of the exercise. By this point, the class has moved in one class period from conjugation-checks, to written expression, then to peer communication responding to questions and finally to openended data analysis.

If an instructor wishes, this can extend further to involve authentic or instructionallydeveloped internet-based cultural materials regarding what children or college students do on a typical day in different parts of the world. This creative and communicative exercise can therefore be made into a cultural one as well.

The Communication Before Grammar exercise, while seemingly involved, generally only takes about ten minutes of class time (including time to log in) and is thus easily meshed into a lesson plan. What it provides the instructor, among other things, is a baseline of the class understanding of a given grammar or lexical (or even cultural) point in a short span of time. This can help gauge the appropriate difficulty level for follow-on activities. For instance, it can help the instructor choose between a more open-ended cultural activity if comprehension and mastery is high, and a more controlled mechanical activity if comprehension and mastery are low. This approach provides the students many benefits, including their active use of the material, a series of metalinguistic tools to analyze their and their peers' language and an easy segue to effective communication with peers.

\section{Example 4: Using Course Projects and a Cyclical Approach to the PERIA Model (Mathematics Course)}

The final example demonstrates how the PERIA process is adapted for a mathematics course, historically dominated by lectures, by using projects and a cyclical approach to reflection and integration. Many cooperative learning advocates recognize the necessity, particularly in technical fields, of combining lectures and experiential learning in order to convey the large amount of technical information that must precede opportunities for students to experience and reflect on newly acquired knowledge. Cooperative learning in technical courses, therefore, often takes the form of brief group activities interspersed throughout a lecture to involve the students without sacrificing important content (Bligh 2000; Springer et al. 
1997; Felder \& Brent, 1994; Felder et al. 2000; Miettinen, 2000).

This example of using group projects in a senior level Linear Regression course for Operations Research and Computer Analysis majors, demonstrates how traditional lecture instruction and homework in a content dominated technical course can be supplemented with the PERIA process. The cycle (Figure 3) demonstrates the recursive nature of mathematical problem solving that often involves pursuing a solution method, reflecting on the outcome of the method, integrating the results into the bigger picture, and repeating the process with a revised solution method as needed.

\section{Stage 1: Preparation}

Preparation consists of classroom lectures with group work incorporated during class as appropriate and as time permits. The amount of time available for classroom activities often depends on student participation with respect to reading the material prior to class. Lectures are accompanied by traditional homework assignments requiring students to demonstrate their understanding of the concepts and apply what they've learned to textbook problems. The students are allowed to collaborate on the homework assignments and to use computer software for most of the computations.

The Linear Regression Project experience has evolved over time and currently begins approximately one-third of the way through the course with group formulation and data selection, followed by a three part progressive assignment. The instructor can decide whether to assign groups or allow students to self-select; there are inherent advantages and disadvantages to each approach. Groups of two to three students seem to promote active collaboration between group members while reducing opportunities for under-performers to hide in a larger group.

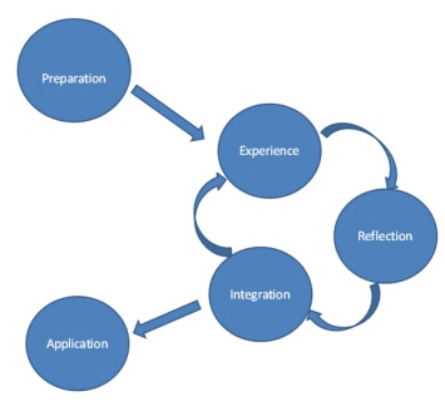

Figure 3. The PERIA Process as a Cycle

\section{Stage 2: The Experience}

The student groups are allowed to select their own data related to a topic of interest. Specifically, they are instructed to find a quantitative response variable, five quantitative predictor variables and a sixth qualitative predictor variable. The project requires them to apply the seemingly abstract mathematical concepts covered in class to an imperfect example of their own choosing. Using real data develops their critical thinking as the students seek to find and understand relevant, useful data they can use to apply what they have learned. Students often select sports related data - hoping to predict winning percentages using certain offensive and defensive statistics relevant to that sport, with gender or league membership as their qualitative variable. Allowing the student groups to select their own data increases their level of interest in the project and requires them to integrate their previous knowledge of the selected topic into the new experience.

\section{Stage 3: Reflection}

After the initial experience of selecting their data, students begin the first iteration of the reflection and integration cycle as they determine which data are useful and which are hard to collect. They then present their selected data to the instructor, who continues the PERIAcycle by advising them of possible pitfalls. Without delving into the details of Linear Regression, some examples of pitfalls include not having enough data, overly dependent data, a qualitative variable with too many response options, or proceeding with raw data that should have been transformed. This initial data review sends some groups back to the "Preparation" step to select data that is more suitable for the Linear Regression Project. 


\section{Stage 4: Integration}

The students then have approximately four weeks to conduct and submit the first part of the project, a Simple Linear Regression analysis. They select two of their quantitative predictor variables and create, analyze and compare two separate models for the same response variable, each using one of the predictor variables. The analysis is submitted to the instructor along with a determination and explanation of which model is better. The assessment instrument requires the students to integrate the experience of their real-world data with everything they've learned in the course about Simple Linear Regression, and to think about which aspects of their models are more important for their situation in order to decide which is better. The write up for this part is informal but must be thorough and comprehensive. The integration of concepts (or lack thereof) is particularly apparent as students try to determine which model is better in the Simple Linear Regression analysis and again for Multiple Linear Regression later in the project. Sometimes one model fits better for some measures or aspects of the analysis but another model appears better using different measures or aspects. The students must decide which deviations from an ideal model are less problematic for their particular analysis and explain the reasons for their model selection.

Approximately two weeks later, after receiving feedback from the instructor, the students present their analysis in class. This allows the students to correct errors from their prior submission, learn from the analysis of the other groups, and practice critical communication skills associated with presenting the results of a technical analysis. The student audience further participates by asking questions, grading the other students on their presentation skills, and hearing the feedback from the instructor. Students are graded on both the information presented as well as their presentation skills.

\section{Stage 5: Application}

Near the end of the semester, approximately four weeks after presenting their analysis in class, the groups submit a Multiple Linear Regression analysis paper that incorporates the material learned in the second half of the course to determine the best Multiple Linear Regression model and also analyze the relationship between the qualitative variable and the response variable. This part of the project also helps the students learn how to communicate technical information in writing which is another important skill for technical majors. Half of the paper grade is based on their analysis while the other half is based on the writing and logical flow and organization of the information presented. The required paper format is the same one used the following semester in their senior capstone course.

\section{Re-iterative use of the PERIA process}

In addition to using the PERIA process for the Linear Regression Project as a whole, students follow this process during each stage, perhaps several times. Reflecting during their initial data collection experience sometimes sends students back to the "Preparation" stage to select new data. Similarly, at each stage of the project, students may discover that they need to revise the approach, thus returning to the "Experience" stage of the PERIA process.

This type of reflection is required during each stage of the project. Group members must mutually agree on their process and assessment of the situation, determine whether they adequately addressed that part of the project assignment, and decide when they are ready to draw conclusions. The better groups will reflect deeply, identify numerous questions associated with their data and the material, use the textbook, and ask the instructor for help in answering those questions. Even the less dedicated groups, however, must reflect on the feedback provided at each stage in order to correct any errors for the next submission. Data concerns must be addressed prior to analysis, analysis errors must be corrected prior to presenting, and the final paper requires them to conduct additional analyses using more complicated but related processes to those used earlier in the project. Hopefully, the students will improve their level of understanding of the material by reflecting not only on what has gone well or poorly at each stage, but more importantly on why.

In addition to integrating their own perspective with those of their team members', students must integrate their real-world data with the course concepts as they finalize their analysis, draw conclusions, make recommendations and present their results to the class and instructor through their presentation and paper. The instructions require the students to provide not only the mathematical solution, but also a managerial interpretation that is 
designed to convey their results to a non-mathematician. While the process of integration is most evident when groups are determining which model works best in the Simple Linear Regression analysis, each stage of the project requires the students to apply what they've learned in class and incorporate the lessons learned in the previous parts of the project. When such integration is not possible, this observation spurs groups to return to earlier stages in the PERIA cycle as the students struggle to understand, revise, and explain their experience in their presentation or paper.

The application stage continues during the final exam, during the next semester's senior capstone projects, and hopefully beyond graduation whenever they conduct or critically read data analysis. The final exam provides new data with various regression output results that the students are required to use to answer questions covering many of the same topics incorporated into the projects. Often, the questions tell students to 'explain' their answers; student responses allow the instructor to assess the level of understanding of the concepts in addition to the correctness of the numerical answer.

The following semester, the same students are assigned into different groups to conduct senior capstone consulting projects. Although only a few projects use Linear Regression as part of their mathematical solution, the students bring together their different perspectives and lessons learned about data analysis and communicating results during the Linear Regression Project. All of the capstone projects are presented to a cross section of faculty, students, sponsors and visitors during a senior symposium day and the same Linear Regression report structure is used for their more extensive final paper that is provided to the project sponsors.

The Linear Regression Project guides the students to use course concepts to apply mathematical analysis to real-world problems of interest using a cyclical and re-iterative approach to the experience, reflection and integration stages of the PERIA process. The project requires students to revisit the experience stage at least four times during data selection and the three parts of the assigned project. Learning to work with real data, rather than textbook created examples, requires a higher level of critical thinking that is essential for any student of applied mathematics. By working within the team environment to achieve a successful resolution to a non-textbook and sometimes initially unclear problem, students are forced to reflect upon and integrate the breadth of material learned throughout the course. The communication skills learned along the way also help prepare the students for their capstone course the following semester, during which they are required to apply mathematics and computer analysis to develop recommendations in response to a problem statement provided by their Coast Guard project sponsor in a consulting environment. This application of the PERIA model demonstrates that the model can be effectively implemented in technical fields of study using a re-iterative approach to the PERIA stages that takes place over a longer time scale than a single class or textbook chapter.

\section{Assessment of the PERIA Model}

Assessing the PERIA model and its impact on students learning has been an important component of the educational process in the Economics course at U.S. CGA. A rubric approach to assess the effectiveness of the PERIA model has been adopted to illustrate the evidence of students' and faculty's satisfactions with students' learning. The PERIA assessment of students' and instructors' satisfaction with the PERIA process has been completed across several sections of economics course during several semesters. The instrument and the results obtained for the four semesters during two academic years, 2016-2017 and 2017-2018, are summarized in Table 5 and Table 6 respectfully.

Table 5.Assessment Instrument: Students' and Teachers' Satisfaction with the PERIA Model

\begin{tabular}{|c|c|c|}
\hline \multirow{2}{*}{ PERIA MODEL } & $\begin{array}{c}\text { Learner's } \\
\text { Self-evaluation }\end{array}$ & $\begin{array}{l}\text { Teacher's } \\
\text { Evaluation }\end{array}$ \\
\hline & \multicolumn{2}{|c|}{$\begin{array}{c}\mathrm{D}=\text { Developing } \mathrm{C}=\text { CompetentE }=\text { Exemplary } \\
(\text { Circle one for each stage })\end{array}$} \\
\hline How PREPARATION stage contributed to your learning process? & D C E & D C E \\
\hline How EXPERIENCE stage contributed to your learning process? & D C E & D C E \\
\hline How REFLECTION stage contributed to your learning process? & D C E & D C E \\
\hline How INTEGRATION stage contributed to your learning process? & D C E & D C E \\
\hline How APPLICATION stage contributed to your learning process? & D C E & D C E \\
\hline
\end{tabular}




\section{D-Developing; C-Competent, E - Exemplary}

Source: Management Department, the U.S. Coast Guard Academy.

As illustrated in Table 5, both the students and the faculty were asked to assess how each stage of the PERIA model contributed to students' satisfaction and hence learning in the Economics course where experiential learning was delivered with the use of games and simulations. The results of the assessment instrument present both students' and faculty's satisfaction with the PERIA model during experiential learning. The satisfaction was measured using three levels: D - Developing; C-Competent, E-Exemplary. All five stages of the PERIA model were assessed.

Table 6. Survey Results: The Assessment of the PARIAModel

\begin{tabular}{|l|l|l|}
\hline \multirow{2}{*}{ PERIA MODEL } & \multicolumn{1}{|c|}{$\begin{array}{c}\text { Learner's Satisfaction } \\
\text { Self-evaluation }\end{array}$} & $\begin{array}{c}\text { Teacher's Satisfaction } \\
\text { Evaluation }\end{array}$ \\
\cline { 2 - 3 } & \multicolumn{2}{|c|}{ (Circle one for each stage) } \\
\hline PREPARATION & $\mathrm{C}=25 \% \mathrm{E}=75 \%$ & $\mathrm{C}=40 \% \mathrm{E}=60 \%$ \\
\hline EXPERIENCE & $\mathrm{C}=10 \% \mathrm{E}=90 \%$ & $\mathrm{C}=30 \% \mathrm{E}=70 \%$ \\
\hline REFLECTION & $\mathrm{C}=20 \% \mathrm{E}=80 \%$ & $\mathrm{C}=25 \% \mathrm{E}=75 \%$ \\
\hline INTEGRATION & $\mathrm{D}=5 \% \mathrm{C}=35 \% \mathrm{E}=60 \%$ & $\mathrm{C}=10 \% \mathrm{E}=90 \%$ \\
\hline APPLICATION & $\mathrm{C}=40 \% \mathrm{E}=60 \%$ & $\mathrm{C}=0 \% \mathrm{E}=100 \%$ \\
\hline
\end{tabular}

D-Developing; C-Competent, E-Exemplary

Source: Management Department, the U.S. Coast Guard Academy.

According to Table 6, the survey results illustrate that all students evaluated their satisfaction at a lower level than the faculty members. The Integration Stage had $5 \%$ of students evaluating it at the Developing level. Both students' and faculty's evaluations of all other stages of the PERIA model was at the Competent level and the Exemplary level. However, the majority of satisfaction level for all stages at both students' and faculty's level was documented at the Exemplary level. Those results are satisfactory and document that there is still some room for the improvement, and in particular at the last stages of the PERIA model, Integration and Application. Students were provided with the results of the assessment process. Each student was able to contrast her or his own satisfaction level as well as the faculty's assessment. We also provided an opportunity for an open-end response. Some students expressed that the PERIA model has been an outstanding process allowing students to progressively learn the basic economics concepts through the process of experiencing, reflecting, integrating, and applying. Some students' comments included:

"I truly enjoyed playing games in this class. The process we used was clear what we were expected to do and learn. Hope we can have more class activities structed that way."

"What a great opportunity to engage students in learning where we are actually doing everything, and our teacher monitors our progress. When we failed at some stages and we were helped to recover quickly."

"It was a great informative way of learning from the experience and with the simultaneous feedback from an instructor."

\section{Conclusions}

Lecturing may be appropriate for disseminating information, but current research on college teaching and learning suggests that the use of a variety of active and experiential instructional strategies can positively enhance student learning. Teaching effectively involves not only using tools, techniques, and strategies to improve student learning but also understanding how students learn, how they process information, what motivates them to learn more deeply, and what impedes the learning process. The authors believes that all students can move toward becoming reflective learners with the use of games and simulations, small group or class discussions, computer-aided creative exercises, and course projects. Each of these activities can be structured using the five-stage PERIA model that can successfully be used in 
any undergraduate classroom. It offers a strategy for developing a more reflective approach to processing experiences. The paper contributes to the existing literature on experiential learning by arguing that learning from experience becomes more effective if it is coupled with Preparation replacing Pre-experience and adding Application into a RIM Model. The PERIA Process makes experiential learning more productive and turns learning into high rates of learning. Drawing on PERIA Process, the paper argues that experiential learning can be augmented by deliberately structuring learning processes where students must be prepared for experiential learning. Also, at the end of the experiential learning students must be allowed to go beyond integration stage to apply and reflect upon their experiential learning.

Cooperative or active learning activities such as games, simulations, small group or class discussions, and course projects are pedagogical strategies that encourage students to work together for the achievement of a common goal. When integrating cooperative strategies into a course, careful planning and preparation are essential to achieve experiential and reflective learning. Understanding how to form groups, ensure positive interdependence, maintain individual accountability, resolve group conflict, develop appropriate assignments, and manage active learning environments are all critical to the achievement of a successful cooperative learning experience. This paper has demonstrated that with the use of the PERIA process, learning can be enhanced when students become actively involved throughout the learning process. All learning strategies can be designed to engage students in active learning processes that stimulate reflective thinking and a greater awareness of other perspectives. Our assessment instrument also documents that the PERIA process provides students with an effective learning process.

\section{References}

Ambrose, S., Bridges, M., DiPietro, M., Lovett, M., \& Norman, M. (2010). How learning works: 7 researchbased principles for smart teaching. San Francisco, CA: Jossey-Bass.

Bligh, D.A. (2000). What's the Use of Lectures? San Francisco, CA. Jossey-Bass Publishers.

Border, L. L. B. (2007). Understanding learning styles: The key to unlocking deep learning and in-depth teaching. NEA Higher Education Advocate. 24(5), 5-8.

Burston, J.(2013). MALL: Future Directions for BYOD Applications. IALLT Journal.43(2), http://www.iallt.org/iallt_journal/language_learning_technology

Clancey, W. J. (1995). A tutorial on situated learning. Retrieved from: http://methodenpool.unikoeln.de /situierteslernen/clancey_situated_learning.PDF

Cohen, E.G. (1994). Restructuring the classroom: Conditions for productive small groups. Review of Educational Research, 64, 1-3

Cooper, J. and R. Mueck (1990). Student Involvement in Learning: Cooperative Learning and College Instruction. Journal on Excellence in College Teaching, 1, 68-76.

Dewey, J. (1916). Democracy and Education. New York: MacMillan.

Felder, R.M. \& Brent, R. (2001). Effective Strategies for Cooperative Learning. The Journal of Cooperation and Collaboration in College Teaching, 10(2), 69-75.

Felder, R.M. \& Brent,R. (1994) Cooperative Learning in Technical Courses: Procedures, Pitfalls, and Payoffs. Work supported by National Science Foundation Division of Undergraduate Education Grant DUE9354379.

Felder, R.M., Woods, D.R., Stice, J.E. \& Rugarcia, A. (2000). The Future of Engineering Education II. Teaching Methods that Work. Chemical Engineering Education, 34(1), 26-39.

Hativa, N. (2000). "Lecturing and Explaining." Chapter in Teaching for Effective Learning in Higher Education. Dordrecht, The Netherlands: Kluwer Academic Publishers.

Holter, N.C. (1994). Team Assignments Can Be Effective Learning Techniques. Journal of Education for Business, 70(November-December), 73-76.

Hutchinson, C. J.,\& Allen, C, W.(1997). The Reflection Integration Model: A Process for Facilitating Reflective Learning. The TeacherEducator, 32(4), 226-234.

Jarvis, P. (1987). Adult Learning in the Social Context. London: Croom Helm. 
Jarvis, P. (2004). Adult Education and Lifelong Learning. Theory and Practice (3rd edition). London: Routledge Falmer.

Jensen, P. \& Kolb, D. (1994). Learning and development. In M. Keeton (ed.), Perspective in experiential learning. Chicago: Council for Adult and Experiential Learning (CAEL).

Johnson, D., \& Johnson R. (1989). Cooperation and Competition: Theory \& Research. Edina, MN: Interaction Book Company.

Johnson, D., \& Johnson, R. (1991). Creative Learning Cooperation in the College Classroom. Edina, MN: Interaction Book Company.

Johnson, D. W., Johnson R. T., Holubec, E. J. (1991). Basic elements of cooperative learning. Principles of Cooperative Learning. Edina, MN: Interaction Book Company, 1991.

Johnson, D. W., \& Johnson, R. T. (2008). Social Interdependence Theory and Cooperative Learning: The Teacher's Role. In R. M. Gillies, A. Ashman \& J. Terwel (Eds.), Teacher's Role in Implementing Cooperative Learning in the Classroom (pp. 9-37). New York, U.S.A: Springer.

Kirkley, S. E. \& Kirkley, J. R. (2005). Creating next generation blended learning environments using mixed reality, video games and simulations. Linking Research \& Practice to Improve Learning, 49(3), 42-89.

Klopfer, E. (2005). Developing games and simulations for today and tomorrow's tech savvy youth. Linking Research \& Practice to Improve Learning, 49(3), 33-41.

Kolb, D. (1984). Experiential learning: Experience as the source of learning and development. Englwood Cliffs, NJ: Prentice Hall.

Kolb, A. Y. \& Kolb, D. A. (2009). On becoming a learner: The concept of learning identity. In Bamford-Rees et. al. (Eds.), Learning never ends: Essays on adult learning inspired by the life and work of David O. Justice Chicago, IL: CAEL Forum and News*

Kolb, D. A. (2007). The Kolb learning style inventory—version 3.1: LSI workbook. Boston, MA: Hay Learning Transformations.

Liang, T. (2002). Implementing Cooperative Learning in EFL Teaching: Process and Effects, (Doctoral dissertation, National Taiwan Normal University). [Online] Available: http://www.asian-efl-journal.com/ Thesis_Liang_Tsailing.pdf

Lewis, L. \& Williams, C. (1994). Experiential Learning: Past and Present. In Jackson, L. and R. Caffarella (eds) (1994). Experiential Learning: A New Approach, no. 62 of the New Directions for Adult and Continuing Education Series. San Francisco: Jossey-Bass.

Maier, M.,\& Keenan, D. (1994). Cooperative Learning in Economics. Economic Inquiry, (April): 358-361.

Messick, S. (Ed.) (1976), Individuality in Learning, Jossey-Bass, San Francisco, CA.

Omaggio-Hadley, A. (2001). Teaching Language in Context. University of Illinois, Urbana-Champagne: Cengage Learning.

Rice, G. T. (1990). Effective Teaching Techniques for College Classes. Adventist Education, 45(1), 21-23.

Rotenberg, R. (2005). The Lecture Classroom. Chapter in The Art and Craft of College Teaching: A guide for New Professors and Graduate Students. Walnut Creek, CA.

Sims, R., \& Sims, S. (1995), The Importance of Learning Styles: Understanding the Implications for Learning Course Design and Education, Greenwood Press, Westport, CT.

Smith, K., \& Johnson, D. (1992). Cooperative Learning and Positive Change in Higher Education, In A. Goodsell, (Eds.), Collaborative Learning: A Source-book for Higher Education (34-36). University Park, PA: National Center For Post-secondary Teaching, Learning, \& Assessment.

Smith, V. (1992). An Experimental Study of Comparative Market Behavior. Journal of Political Economy, 70(2), 111-137.

Springer, L., Stanne, M.E. and Donovan, S.S. (1997). Effects of Small-Group Learning on Undergraduates in Science, Mathematics, Engineering, and Technology: A Meta-Analysis. Research Monograph No. 11, National Institute for Science Education, University of Wisconsin-Madison, funded by the National Science Foundation, Cooperative Agreement No. RED-9452971.

Stein, D. (1998). Situated learning in adult education. Retrieved from: http://www.ericdigests.org/19983/adult-education.html

Weimaer, M. (1990). Improving College Teaching: Strategies for Developing Instructional Effectiveness. San Francisco, CA: Jossey-Bass. 
Wenglinsky, H. (2000). How Teaching Matters: Bringing the Classroom Back Into Discussions of Teacher Quality. Washington, DC: Educational Testing Service.

Wenglinsky, H. (2002). How Schools Matter: The Link Between Teacher Classroom Practices and Student Academic Performance. Education Policy Analysis Archives, February 13. 10(12).

Wilson, B., G., \& Myers, K. M. (2000). Situated Cognition in theoretical and practical context. In D. Jonassen \& S. Land (Eds.), Theoretical foundations of learning environments (pp. 57-88). Mahwah, NJ: Erlbaum.

Wolfe, D. E. \& Byrne, E.T. (1975). Research on Experiential Learning: Enhancing the Process," Simulation Games and Experiential Learning in Action, R.H. Buskirk (ed). 325-336.

VARK, A Guide to Learning Styles.http://www.vark-learn.com Springfield, MO.

Zapalska, A. \& Brozik, D. (2001). Learning market skills through simulation. Journal of Private Enterprise, Spring: $56-70$. 